\title{
High Resolution and Tandem Fourier- Transform Mass Spectrometry with Californium-252 Plasma Desorption
}

\author{
Evan R. Williams and Fred W. McLafferty \\ Chemistry Department, Baker Laboratory, Cornell University, Ithaca, New York, USA
}

\begin{abstract}
For ions formed by plasma desorption (PD) in a Fourier-transform mass spectrometer, high resolution measurements are demonstrated, such as 65,000 (FWHH) for the protonated molecular ion of gramicidin S (MW 1140.7). Resolution is substantially improved by delaying measurements until a significant ion concentration has built up in the cell, and by collisionally deactivating the orbital kinetic energy of the ions. This also makes the ions available for subsequent dissociation steps, so that tandem mass spectrometry can be demonstrated for PD ions. With this for larger ions, collisionally activated dissociation (CAD) is effected with $>85 \%$ efficiency. The CAD spectra of $(\mathrm{M}+\mathrm{Na})^{+}$and of fragment ions from the PD of gramicidin $S$ provide structurally useful information. ( $\mathrm{Am}$ Soc Mass Spectrom 1990, 1, 427-430)
\end{abstract}

$\longrightarrow$ ince its introduction in 1974 by Torgerson et al. [1], plasma desorption (PD) has become an increasingly popular technique for the analysis of large molecules [1-13]. Desorption matrices such as nitrocellulose [4-6] and glutathione $[7,8]$ reduce ion internal energy, promoting multiple protonation and formation of molecular ions with little fragmentation. Desorption of peptides as large as bovine ovalbumin (MW 45,000) has been demonstrated, with $(\mathrm{M}+$ $4 \mathrm{H})^{4+}$ the most abundant ion in this spectrum [5]; multiple charging extends the mass range of a spectrometer with an upper $m / z$ limit. However, the low rate of ion production of $\mathrm{PD}$ requires multichannel detection for efficient recording of spectra, a major reason that time-of-flight mass spectrometry (TOF/MS) has been used for PD [1-9]. For many important compounds such as large peptides, PD produces little fragmentation, providing primarily molecular weight information. However, limited structural information can be obtained [3] using in situ reactions on the PD sample [6].

For further structural characterization of the PDproduced molecular ions, especially from mixtures, capabilities for higher resolution and tandem mass spectrometry $[14,15]$ are desirable; for these, Fouriertransform mass spectrometry (FTMS) excels, and also has the multichannel detection capability [16-18]. Tabet et al. [10] first combined PD with FTMS, producing $(\mathrm{M}+\mathrm{K})^{+}$ions from leu-enkaphalin (MW 555); Viswanadham et al. [11] obtained PD spectra from lower molecular weight salts. This method has been

Address correspondence to Fred W. McLafferty, Chemistry Department, Baker Laboratory, Cornell University, Ithaca, NY 14853-1301. applied to a variety of peptides up to $m / z 2300[12$, 13], with 10,000 resolution obtained for gramicidin $S$ (MW 1141), but with weak signals $\left(\sim 10^{3}\right.$ ions/s) requiring long times (up to 20 hours) for ion collection and repeated spectral measurement. Although this resolution is better than that currently achieved in $\mathrm{PD}$ TOF/MS( $\sim 8100$ resolution for $\mathrm{CsI}_{2}^{-}$at $\mathrm{m} / z 387$ [9]), it is well below that demonstrated for FT $(150,000$ resolution at $m / z 1200$ [18]). This lowered FT resolution was attributed to frequency shifts (frequency is inversely proportional to mass) occurring between signal averaged spectra [13].

Recently, the FTMS signal intensity from large ions has been greatly improved by not ejecting residual ions ("quench-off") between measurements [19], with signal-to-noise $(S / N)$ improved by $\sim 100 \times$ with 1000 signal-averaging events. Collisions of large ions with background molecules cause negligible scattering, only reducing the ions' kinetic energy; repeated such reduction of the orbital velocity returns the ions to the center of their orbits so that they are available for redetection in subsequent measurements. As described here, this higher sensitivity, with minimization of frequency shifts and improvements to the vacuum system, is used to increase substantially the resolution of $\mathrm{PD}$ spectra and to measure the first tandem mass spectrometry (MS/MS) spectra of ions formed by PD.

\section{Experimental}

As described previously [13], a prototype Nicolet FTMS-2000 (2.86 T) in an elongated single cell configuration [20] was used with a $50 \mu \mathrm{Ci}$ Californium-252 


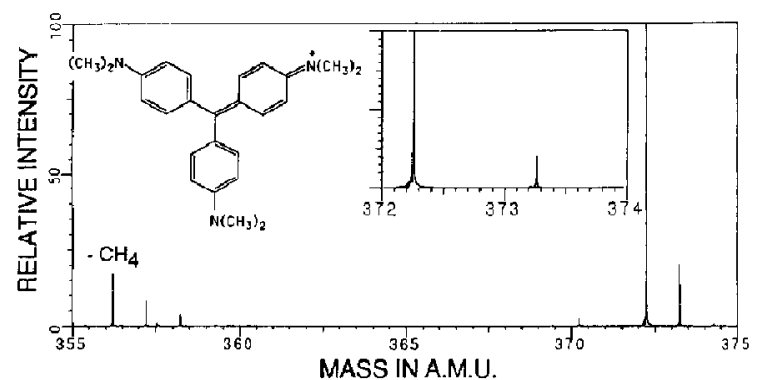

Figure 1. ${ }^{252} \mathrm{Cf}$ PD-FTMS spectrum of crystal violet, averaging 306 quench-off scans. Inset, 60,000 resolution for $\mathrm{C}_{25} \mathrm{H}_{30} \mathrm{~N}_{3}, m / z$ 372.2440 .

$\left({ }^{252} \mathrm{Cf}\right)$ source (Isotope Products Laboratories, Burbank, CA, covered with an electron-beam-welded Ni foil allowing baking to $250^{\circ} \mathrm{C}$ ) configured for front-side desorption. The vacuum system, modified by the addition of a StarCell ion pump with a non-evaporable getter $(420 \mathrm{~L} / \mathrm{s}$, Varian Associates, Lexington, MA) and diffusion-pumped inlet system, made possible operation at pressures near $10^{-10}$ torr with baking before sample introduction.

The copper tip of the sample probe was electrosprayed first with an acetone solution of nitrocellulose $\left(\sim 60 \mu \mathrm{g} / \mathrm{cm}^{2}\right)[4]$ and then with a methanol solution containing equimolar amounts of the sample and reduced glutathione $[7,8]$. An optimum signal was obtained with the probe tip inserted to within a few millimeters of the front trapping plate, a 3-V trapping potential, and the probe and ${ }^{252} \mathrm{Cf}$ source grounded. Designated spectra were obtained with the quench-off ion remeasurement technique [19] and collisionally activated dissociation (CAD) spectra with pulsed-valve introduction of $\mathrm{Ar}[20,21]$.

\section{Results and Discussion}

Improved resolution. Elimination of the quench pulse between signal-averaged spectra makes possible repeated measurements of the same ions if they are sufficiently large [19]. For $m / z 372$ ions from crystal violet [19] the signal increase from 30 such quench-off scans and from using heterodyne (narrow band) operation (measuring a much narrower range of frequencies for much longer times) makes possible 220,000 resolution (FWHH), but with relatively poor $S / \mathrm{N}$ and some split (frequency shifted) peaks. Increasing the number of signal averaged scans tenfold (Figure 1) improves the $\mathrm{S} / \mathrm{N}$ and consolidates the split peaks, but reduces the resolution to 60,000 .

This resolution reduction could arise from a shift in frequency with increasing ion concentration in the cell [22]. In addition, ions that are redetected many times [19] may change their average position relative to the center of the cell $x, y$-plane. Wang and Marshall [23] have shown that this causes a frequency shift; the radial electric field produced by the potential on the

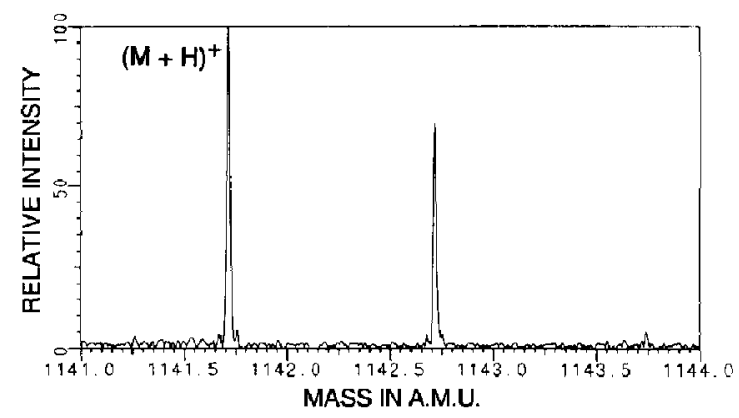

Figure 2. Single scan spectrum of gramicidin $S(500 \mathrm{~s}$ ion collection time), 65,000 resolution.

trapping plates decreases the effective magnetic field strength with increasing distance from the magnetic axis. To avoid these problems, generated ions from gramicidin $S$ were accumulated in the cell for $500 \mathrm{~s}$ and a single spectrum measured. The RF transient for this spectrum was longer than $10 \mathrm{~s}$, resulting in 65,000 resolution (FWHH, Figure 2). Thus the start of quench-off signal averaging should be delayed until a similarly substantial ion concentration has been achieved. Current work on improved cell designs [23-25] promises to reduce electrostatic field inhomogeneities significantly.

Tandem mass spectrometry. The unusually low generation rate $\left(\sim 10^{3} \mathrm{~s}^{-1}\right)$ of $\mathrm{PD}$ ions also creates a problem for their CAD [26]. Using 60 measurement cycles with $60 \mathrm{~s}$ between each provided sufficient CAD information to determine the amino acid sequences of the $\mathrm{m} / \mathrm{z}$ 197 and 311 fragment ions of gramicidin $S$ (Figure 3), $(\text { ProVal }+\mathrm{H})^{+}$, and $(\text {ProValOrn }+\mathrm{H})^{+}$, respectively. The dissociation efficiency was $\sim 60 \%$ for $m / z 197$, but only $-45 \%$ for $m / z 311$, despite a much higher collision energy ( $54 \mathrm{eV}$ versus $12 \mathrm{eV}$ ). Repeated measurement of the CAD product ions after collisional de-excitation back to the magnetic axis [19] was rela-

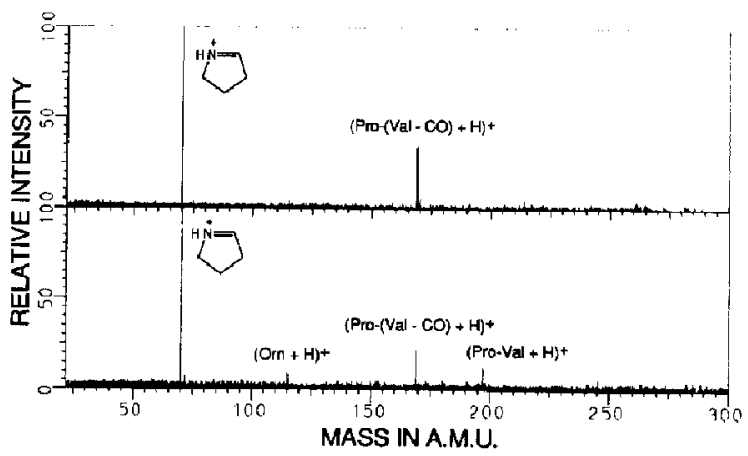

Figure 3. CAD spectra $(601-\mathrm{min}$ measurement cycles, pulsed Ar introduction) of protonated fragment ions of gramicidin S: top. $(\text { ProVal }+\mathrm{H})^{+}, 12 \mathrm{eV}$ collision energy; bottom, (ProValOrn $+(\mathrm{H})^{+}, 54-\mathrm{eV}$ collision energy. 


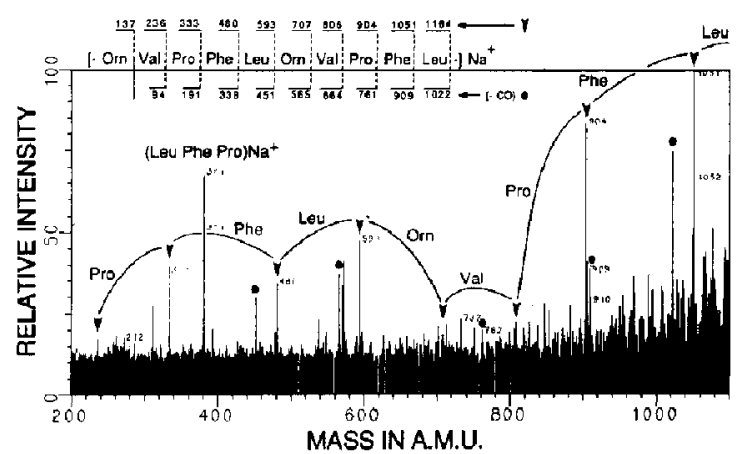

Figure 4. 71-eV CAD spectrum of $(\mathrm{M}+\mathrm{Na})^{+}$of gramicidin $\mathrm{S}$, 691 1-min measurement cycles.

tively ineffective due to the high scattering losses for such small ions.

For the $m / z 1164(\mathrm{M}+\mathrm{Na})^{+}$ions formed by PD of gramicidin $\mathrm{S}$, CAD produces no daughter ions measurable with quench-on; CAD efficiency decreases with increasing molecular weight $[27-29]$, especially in FTMS where the maximum kinetic energy also decreases with mass $[20,30]$. However, removal of the quench pulse greatly improves the daughter ion signals, which provide nearly complete sequence information (Figure 4). The sum of daughter ion intensities is actually 2.1 times that of $(\mathrm{M}+\mathrm{Na})^{+}$measured with quench-on, far higher than expected from the above $45 \%$ value for $m / z 311$. Now the undissociated molecular ions $(m / z 1164)$ should be collisionally relaxed back to the center of their orbits with high efficiency between measurement cycles so that they are available for dissociation in subsequent steps. In addition, fragment ions above $m / z 900$ (ions below this were ejected from the cell prior to precursor ion dissociation in each measurement cycle) should also relax to the center with high efficiency and be remeasured in subsequent scans; without these, the CAD efficiency is $\sim 85 \%$, indicating that the majority of the signal for the higher mass fragment ions is due to remeasurement. The 2-s delay after $\mathrm{CAD}$ excitation appears to be sufficient to produce significant $x, y$ plane relaxation because of the increased pressure of the pulsed collision gas, so that molecular ions are not ejected from the cell with the subsequent detection excitation. Dissociation efficiencies of large multiply charged ions formed by electrospray ionization [31, 32] are currently under study.

\section{Conclusions}

Despite the unusually low rate of peptide ion formation by $\mathrm{PD}$, high resolution and MS/MS measurements are possible with FTMS in part due to its unusual ion storage capabilities. The CAD efficiency of large ions can be greatly improved by repeating the CAD process after collisional relaxation of the undissociated precursor ions back to the $x, y$-axis. This method should be equally applicable to other dissociation techniques in FTMS such as photodissociation $[20,33]$, electron impact excitation of ions from organics [34], and surface induced dissociation [35].

\section{Acknowledgments}

Generous financial support for this research was provided by the National Institutes of Health, grant GM-16609, with instrumentation by them and the National Science Foundation, grant CHE-8303340, and by Perkin-Elmer through sponsorship of an American Chemical Society Analytical Division Fellowship (for ERW).

\section{References}

1. Torgerson, D. F.; Skowronski, R. P.; Macfarlane, R. D. Biochem. Biophys. Res. Commun. 1974, 60, 616-621.

2. Macfarlane, R. D. Acc. Chem. Res. 1982, 15, 268-275.

3. Roepstorff, P. Acc. Chem. Res. 1989, 22, 421-427.

4. Jonsson, G. P.; Hedin, A. B.; Hakansson, P. L.; Sundqvist, B. U. R.; Save, B. G. S.; Niellsen, P. F.; Roepstroff, P.; Johansson, K.-E.; Kamensky, I.; Lindberg, M. S. L. Anal. Chem. 1986, 58, 1084-1087.

5. Jonsson, G. P.; Hedin, A. B.; I lakansson, P. L.; Sundqvist, B. U. R.; Bennich, H.; Roepstroff, P. Rapid Commun. Mass Spectrom. 1989, 3, 190-191.

6. Chowdhury, S. K.; Chait, B. T. Anal. Biochem. 1989, 180 387-395.

7. Alai, M.; Demirev, P.; Fenselau, C.; Cotter, R. J. Anal. Chem. 1986, 58, 1303-1307.

8. Jardine, I.; Scanlan, G. F.; Tsarbonpoulos, A.; Liberato, D. J. Anal. Chem. 1988, 60, 1088-1096.

9. Della-Negra, S.; Deprun, C.; Le Beyec, Y. Rapid Commun. Mass Spectrom. 1987, 1, 10-11.

10. Tabet, J. C.; Rapin, J.; Poretti, M.; Gaumann, T. Chimia 1986, 40, 169-171.

11. Viswanadham, S. K.; Hercules, D. M.; Weller, R. R.; Giam, C. S. Biomed. Environ. Mass Spectrom. 1987, 14, 43-45.

12. Loo, J. A.; Williams, E. R.; Amster, I. J.; Furlong, J. J. P.; Wang, B. H.; McLafferty, F. W.; Chait, B. T.; Field, F. H. Anal. Chem. 1987, 59, 1880-1882.

13. Loo, J. A.; Williams, E. R.; Furlong, J. J. P.; Wang, B. H.; McLafferty, F. W.; Chait, B. T.; Field, F. H. Int. I. Mass Spectrom. Ion Prac. 1987, 78, 305-313.

14. Tandem Mass Spectrometry; McLafferty, F. W., Ed.; Wiley: New York, 1983

15. Busch, K. L.; Glish, G. L.; McLuckey, S. A. Mass Spectrometry / Mass Spectrometry; VCH Publishers: Deerfield, FL, 1988.

16. Comisarow, M. B.; Marshall, A. G. Chem. Phys. Lett. 1974, 25, 282-283. Marshall, A. G. Acc. Chem. Res. 1985, 18, 316-322.

17. Wilkins, C. L.; Chowdhury, A. K.; Nuwaysir, L. M.; Coates, M. L. Mass Spectrom. Rev. 1989, 8, 67-92.

18. Cody, R. B.; Kinsinger, J. A.; Ghaderi, S.; Amster, I. J.; Mclafferty, F. W.; Brown, C. E. Anal. Chim. Acta 1985, 178, 43-66.

19. Williams, E. R.; Henry, K. D.; McLafferty, F. W. I. Am. Chem. Soc, accepted.

20. Williams, E. R.; Furlong, J. J. P.; McLafferty, F. W. I. Am. Soc. Mass Spectrom., accepted.

21. Carlin, T. J.; Freiser, B. S. Anal. Chem. 1982, 55, 571-574.

22. Wang, T.-C. L.; Marshall, A. G. Int. I. Mass Spectrom. Ion Proc. 1986, 68, 287-301.

23. Wang, M.; Marshall, A. G. Anal. Chem. 1989, 61, 1288-1293.

24. Rempel, D. L.; Ledford, E. B.; Huang, S. K.; Gross, M. L. Anal. Chem. 1987, 57, 2527-2532. 
25. Naito, $\mathrm{X}_{\text {.; }}$ Inoue, M. 36th Annual Conference on Mass Spectrometry and Allied Topics, 1988; pp. 608-609.

26. Levsen, K. In Tandem Mass Spectrometry; McLafferty, F. W., Ed.; Wiley: New York, 1983; pp. 41-66.

27. Neumann, G. M.; Sheil, M. M.; Derrick, P. J. Z. Naturforsch. 1984, 39a, 584-592.

28. Tecklenburg, R. E. Jr.; Miller, M. N.; Russell, D. H. J. Am. Chem. Soc. 1989, 111, 1161-1171.

29. Alexander, A. J.; Boyd, R. K. Int. J. Mass Spectrom. Ion Proc. 1989, 90, 211-240.

30. Cody, R. B.; Freiser, B. S. Anal. Chem. 1982, 54, 1431-1433.
31. Fenn, J. B.; Mann, M.; Meng, C. K.; Wong, S. F.; Whitehouse, C. Science 1989, 246, 64-71.

32. Henry, K. D.; Williams, E. R,; Wang, B, H,; MeLafferty, F. W.; Shabanowitz, J.; Hunt, D. F. Proc. Natl. Acad. Sci., USA 1989, 86, 9075-9078.

33. Hunt, D. F.; Shabanowitz, J.; Yates, J. R. III; Griffin, P. R.; Zhu, N. Z. Anal. Chem. Acta. 1989, 225, 1-10.

34. Cody, R. B.; Freiser, B. S. Anal. Chem. 1987, 59, 1054-1056.

35. Williams, E. R.; Henry, K. D.; Wang, B. H.; McLafferty, F. W. J. Am. Soc. Mass Spectrom., accepted. 